NBER WORKING PAPER SERIES

\title{
BIOLOGY AS DESTINY? SHORT AND LONG-RUN DETERMINANTS OF INTERGENERATIONAL TRANSMISSION OF BIRTH WEIGHT
}

\author{
Janet Currie \\ Enrico Moretti \\ Working Paper 11567 \\ http://www.nber.org/papers/w11567
NATIONAL BUREAU OF ECONOMIC RESEARCH
1050 Massachusetts Avenue
Cambridge, MA 02138
August 2005

The authors are grateful to Bentley MacLeod for helpful comments and to Benjamin Bolitzer, Yan Lee, and Virginia Tnguy for excellent research assistance. Sandra Black, Peter Kuhn, Catherine Weinberger, and seminar participants at Cornell, Syracuse University, UCSB, the 2005 SOLE Meetings, and the 2005 NBER Summer Institute provided helpful comments. This work was supported by NSF grant \#0241861, the Russell Sage Foundation and the Center for Health Research at UC Berkeley. The National Science Foundation is not responsible for any of our results or conclusions. The views expressed herein are those of the author(s) and do not necessarily reflect the views of the National Bureau of Economic Research.

(C)2005 by Janet Currie and Enrico Moretti. All rights reserved. Short sections of text, not to exceed two paragraphs, may be quoted without explicit permission provided that full credit, including $\odot$ notice, is given to the source. 
Biology as Destiny? Short and Long-Run Determinants of Intergenerational Transmission of Birth Weight

Janet Currie and Enrico Moretti

NBER Working Paper No. 11567

August 2005

JEL No. I1

\section{ABSTRACT}

Little is known about the mechanisms underlying the transfer of economic status between generations. This paper addresses the question of whether inter-generational correlations in health contribute to the perpetuation of economic status. We examine inter-generational correlations in birth weight, a key indicator of the health of newborns that we link to future educational attainment and earnings using a unique data set based on California births from 1960s to the present. We use names and birth dates to link the records of mothers and children. We also identify mothers who are siblings. We show that there is a strong intergenerational correlation in the birth weight of mothers and children, but that a measure of household income at the time of the mother's birth is also predictive of low birth weight and that there is an interaction between maternal low birth weight and poverty in the production of low birth weight. Together these findings suggest that intergenerational correlations in health could play a role in the intergenerational transmission of income. Parent's income affects child health, and health at birth affects future income.

Janet Currie

Department of Economics

Columbia University

1022 International Affairs Building - MC

3308

$420 \mathrm{~W} 118^{\text {th }}$ Street

New York, NY 10027

and NBER

currie@simba.sscnet.ucla.edu
Enrico Moretti

Department of Economics

549 Evans Hall \#3880

University of California

Berkeley, CA 94720-3880

and NBER

moretti@econ.berkeley.edu 


\section{Introduction}

Intergenerational correlations in socioeconomic status capture an important dimension of inequality. We want to know not only what fraction of the population is poor, but also whether the children of the poor are destined for a life of misery. Most people find inequality less pernicious when it is not passed on from generation to generation. But while the literature on intergenerational correlations in economic status has made important strides in measurement, less is known about the mechanisms underlying the transfer of economic status between generations. Given the importance of "health capital" for education and earnings, one possibility is that poor health in childhood is an important mechanism for intergenerational transmission of economic status (Case, Fertig, and Paxson, 2005; Currie and Madrian, 1999, Grossman, 2000). ${ }^{1}$

The goal of this paper is to measure intergenerational transmission in health at birth, and to see how it is related to intergenerational correlations in income. We measure health at birth using birth weight, a key indicator of the health of newborns that has been linked to future educational attainment and earnings. We address three questions about intergenerational transmissions in birth weight. First, how large are they and to what extent do simple correlations reflect unmeasured parental characteristics (such as persistent poverty)? That is, do intergenerational correlations in low birth weight merely reflect intergenerational correlations in poverty?

Second, does low birth weight (birth weight less than 2,500 grams) predict lower future economic status? If it does, then it is possible that the intergenerational transmission of low birth weight contributes to the intergenerational transmission of income rather than vice-versa. Third, does the strength of intergenerational transmission vary across SES groups? A significant interaction between SES and low birth weight would suggest that the poor are at increased risk of any negative effects of low birth weight which would speed intergenerational transmission.

To get at these questions, we have assembled a unique data set based on all California births from 1960-1974 and from 1982-2001. We use confidential information about names and birth dates to link the birth records of mothers to the birth records of their children. This data set represents one

1 Eriksson, Bratsberg and Raaum (2005) show that adding measures of the adult child's health status to a typical Solon model of intergenerational correlations in earnings reduces the estimated transmission of earnings by about a quarter, but although they show that children of poor parents are more likely to have adult health problems, they do not explicitly examine the intergenerational transmission of health conditions. 
of the first large-scale attempts to link siblings (i.e. across deliveries to the same mother) and generations (grandmothers, mothers, and children). It has three important features. First, it allows us to identify mothers who are siblings. This is important because we can compare birth outcomes of children born to mothers who are sisters, thus accounting for many important genetic and environmental factors that are common within a family tree. Second, we have created two measures of the mother's socioeconomic status: One measured at the time of her own birth, and one measured at the time of her child's birth. Third, the data set is large, allowing for higher precision than smaller datasets like the Panel Study of Income Dynamics or the British Cohort Studies.

We find that the probability that a child is low birth weight is almost 50 percent higher if her mother is low birth weight. This remains true when we compare mothers who are sisters, and therefore share similar genetic material and some environmental factors. It is also true if we control for income or poverty levels in the mother's zip code of residence at the time of her own birth suggesting that the correlation is not driven merely by intergenerational correlations in maternal economic status. Second, we find that low SES also has an independent effect on the probability of low birth weight, increasing it about six percent relative to the baseline. We also find that the intergenerational transmission of low birth weight may be stronger for mothers who are poor than for mothers who are rich.

Third, we find that being born low birth weight has significant effects on later socioeconomic achievement. In particular, after conditioning on grandmother fixed effects we find that having been born low birth weight is associated with a three percent higher probability of living in a poor area at the time of the delivery of one's own child, and with the loss of about a tenth of a year of education. The effect of low birth weight on later SES is much stronger for women who deliver in high poverty areas than for those who deliver in low poverty areas.

Together with our previous findings that mother's SES affects birth outcomes (Currie and Moretti, 2003), our findings suggest that some of the intergenerational transmission of economic status could be due to intergenerational transmission of low birth weight. If we consider that low birth weight is an imperfect measure of health at birth, and that poor children's health tends to deteriorate relative to the health of other children as they age (Case, Lubotsky and Paxson, 2002; Currie and Stabile, 2003) then our results suggest that poor health in childhood could well be implicated in the intergenerational transmission of poverty. That is, children born to poor adults are 
more likely to have health problems, which in turn makes it likely that they will be poor when they bear their own children.

Taken together, one interpretation of these findings is that biology is not destiny: Social determinants of low birth weight are important. Hence, socially determined differences in health at birth and throughout childhood are likely to play a role in the inter-generational transmission of poverty. Second, they suggest that it will take time to break this inter-generational cycle. Interventions that raise a girl's socio-economic status in childhood are likely to have payoffs in terms of the next generation's health at birth.

The rest of the paper lays out some background regarding the importance of birth weight, previous work on intergenerational correlations, and possible mechanisms in Section 2. Section 3 provides an overview of the data. Section 4 discusses a simple model and our empirical methods. Results are in Section 5. Section 6 concludes.

\section{Background}

\subsection{The Importance of Birth Weight}

Low birth weight has been used as the leading indicator of poor health among newborns for many years. In 1996, the infant mortality rate for babies over 2,500 grams was 2.77 compared to 17.45 for babies between 1,500 and 2,500 grams, and 259.35 for babies less than 1,500 grams (Conley and Bennett, 2001). Follow ups indicate that low birth weight babies have lower scores on a variety of tests of intellectual and social development (Breslau et al. 1994, Brooks-Gunn, Klebanov, and Duncan, 1996). Using data from the British 1958 Birth Cohort study (the National Child Development Study) Currie and Hyson (1996) find that low birth weight was predictive of lower schooling attainments, earnings, and employment probabilities as of age 33, regardless of the parents' socioeconomic status. Behrman and Rosenzweig (2001) use data from the Minnesota Twins Registry to compare higher birth weight infants to their own twins of lower birthweight. They find that the higher birth weight twin is not only taller, but also goes on to get more schooling. They estimate that increasing birth weight by a pound increases schooling by a third of a year. Using data from the Panel Study of Income Dynamics (PSID), Conley and Bennett (2000) find that low birth weight reduces the probability of high school graduation in models that include mother

fixed effects. Conley, Strully, and Bennett (2003) argue that low birth weight babies in low income 
families are at particularly high risk of poor outcomes. ${ }^{2}$

While there is broad agreement that low birth weight is a marker for poor infant health, some observers question whether low birth weight per se has a major causal influence on health. It is possible that it is other factors that are correlated with birth weight, including genes, specific health problems, and/or socioeconomic factors, that are responsible for the high death rates and other adverse outcomes among low birth weight infants (Almond, Chay, and Lee, 2004). In our context, we cannot use alternative measures such as APGAR scores to examine inter-generational correlations in health at birth because they were not routinely reported until 1989. Indeed birth weight is one of the few measures of child health that has been recorded over a long period of time. It is certainly the case that there are many low birth weight babies who are healthy, as well as many babies over 2,500 grams who have serious health problems. Thus, low birth weight is an imperfect measure of health at birth.

For our purposes, what is important is that low birth weight be a meaningful predictor of future outcomes. We demonstrate below that among mothers born into the same family, those with lower birth weights were more likely to be residing in a low income/high poverty zip code and have less education than their sisters when they give birth to their own children many years later. Thus, low birth weight is a meaningful predictor of future socioeconomic status in our data.

\subsection{Intergenerational Correlations in Birth Weight}

There are several studies that document intergenerational correlations in birth weight. Emanuel et al. (1992) use data on first born children from the 1958 British birth cohort study and find significant positive associations between infant birth weight and parent birth weight: Each 100 grams of mother birth weight adds 16 grams to the child's birth weight. They also find that the social class of the maternal grandparents had an independent effect but they do not examine interactions. One caveat to the Emanuel et al. study is that due to the survey design, all of the births in this study had occurred to mothers by age 23.

Coutinho, David, and Collins (1997) use Illinois vital statistics records to show that there is

\footnotetext{
2 In recent years the use of steroid medications to prevent lung disease in premature low birth weight babies has greatly improved their survival rates. However, a recent large-scale randomized controlled trial evaluated the standard use of cortico-steroids and showed that among surviving infants, the treated children were shorter, had lower IQ scores, and had impaired motor skills at school age compared to children who had received lower doses of
} 
an intergenerational correlation in birth weight. Infants born in 1989 to1991 were linked to mothers born between 1956 and 1975. Collins et al. (2002) use the same data to examine correlations in birth weight among US-born and foreign-born white and black women. They document a general increase in average birth weights across generations among native born women. However, among black immigrant women the pattern was the reverse - black immigrant women have babies of higher birth weight than their native born daughters. The rapid improvement of birth weight over time and the differential intergenerational trends suggest that environmental factors are important, but these factors are not directly measured.

A handful of studies look at inter-generational correlations in birth weight and ask whether the mother's socio-economic status at the time of the child's birth can explain the observed correlations. Conley and Bennett (2000) use the Panel Study of Income Dynamics and examine 1,654 singleton births to sample mothers between 1986 and 1992. They find that income during pregnancy has no effect on the risk of low birth weight when the mother's birth weight is controlled, or when family fixed effects are included in the model. However, Conley and Bennett (2001) also estimate models with mother fixed effects and find that if the mother was low birth weight, then income at the time of the birth has a significant impact on the probability that the child is low birth weight. In contrast, we find significant effects of income in the entire sample, which may be due to our larger sample size.

Conley and Bennett (2001) suggest that there is an interaction between poverty at the time of the child's birth and maternal low birth weight in the production of child low birth weight. But their results cannot be regarded as definitive given the very small sample sizes in the PSID. The models for children of low birth weight parents include only 179 children, and only a subset of these would have been born to mothers who experienced a sizeable change in income between births. We investigate these issues using a much larger sample. We also improve on previous studies by including grandmother fixed effects (in order to control for a wide range of background factors within families) and by measuring the mother's SES using income at the time of her own birth as well as at the time of the child's birth.

\subsection{Possible Mechanisms}

medication (Yeh, et al., 2004). 
Intergenerational correlations in birth weight could reflect nature or nurture, or the interaction of the two. Herrnstein and Murray (1994) argue that factors such as intelligence that determine economic status are in-born and are passed from one generation to the next (nature). Certainly some part of the intergenerational correlation in birth weights is likely to be genetic. Taller women tend to have heavier infants, and heavier infants tend to grow up to be taller adults. Emanuel et al. (1992) comment that “the relation of maternal stature to infants' birth weight and/or gestational duration has been demonstrated in all populations studied, including European Caucasions, Blacks, Chinese, Malays, East Indians, and Central American Indians” (page 67).

But the height of a population reflects both its genetic endowment and its long-run nutritional and health status (c.f. Floud, Wachter, and Gregory, 1990; Fogel, 1994). This observation suggests that a mother's socio-economic status in childhood could be related to her future probability of bearing a low birth weight baby, a question we investigate below.

Charles and Hurst (2003) argue that much of the inter-generational correlation in labor market and savings behaviors of parents and children is due to similar learned behaviors (nurture). Similarly, intergenerational correlations in birth weight could also reflect behavioral factors. Many authors have identified a correlation between maternal poverty and low birth weight, although such a link does not necessarily establish any causal relationship. ${ }^{3}$ If the daughters of the poor are more likely than other girls to grow up poor, and if poverty is associated with factors such as smoking, stress, and poor nutrition that lead to lower birth weights, then this might explain the correlation. By controlling more thoroughly than previous studies for possible omitted factors, our study will shed light on this issue.

Drake and Walker (2004) review the literature regarding intergenerational correlations in birth weight and argue that there could also be intergenerational effects of low birth weight that did not operate either through purely genetic or through purely behavioral channels. For example, poor fetal nutrition could lead to low birth weight in the mother which in turn could lead to low birth weight in the next generation through a biological mechanism that was not strictly genetic (this is

\footnotetext{
${ }^{3}$ Gortmaker (1979) was one of the first. Starfield et al. (1991) find an effect for whites but not for blacks, while Duncan and Laren (1990) use find effects of poverty on LBW among blacks. Collins and David (2003) examine 103,072 Chicago births from 1982 and 1983. They find that women in poorer Census tracts have more low birth weight infants, and that racial differences in the fraction of low birth weight births are smaller in these areas.
} 
known as “fetal programming”, see Barker, 1998 and Huxley et al. 2004 for a discussion). Animal studies in rats show that poor nutrition reduces birth weight in the next generation and that after a normal diet is resumed it takes three generations to get back to normal birth weight. Lumey (1992) studied the inter-generational effects of the Dutch hunger winter, when pregnant women were reduced to eating tulip bulbs to survive the Nazi occupation. He reported that mothers exposed to famine in utero went on to deliver lower weight babies as adults. But a subsequent study of the same data (Stein and Lumey, 2000) failed to replicate this finding.

Similarly, many observers reject a simple dichotomy between nature and nurture and investigate interactions between the two. For example, Turkheimer et al. (2003) develop a model of the heritability of IQ in which socioeconomic status matters most at low levels of income, while genes matter most at high levels. Similarly, it might be the case that socioeconomic status has a greater impact on the incidence of low birth weight than on mean birth weights, a question we investigate below. Research by Caspi et al. (2003) and Moffitt et al. (2004) suggest that carriers of specific genes are more likely to develop specific future pathologies only when they are exposed to specific environmental influences. Hence, it is of interest to examine the interaction between maternal low birth weight and maternal socioeconomic status in our models of child birth weight.

\section{The Data}

Our sample is based on individual birth records from California. The data set includes the mother's age, race, state of birth, county of residence and/or hospital of delivery, as well as the child's parity, sex, and birth weight. In addition, the confidential version of the file contains the mother and child's names and the mother's exact date of birth. For mothers who were born in California, it is possible to link their own birth records to those of their infants in order to create an intergenerational data base. The data set also includes some information about fathers, though father information is often missing and the available information is less complete. For example, we do not have the father's first name or state of birth which makes matching more difficult. In what follows, we focus on mothers.

We began with all of the infants born between 1989 and 2001. If the mothers of these infants reported having been born in California between 1960 and 1975 or between 1982 and 1985 (the years for which we have obtained historical birth records) then it was theoretically possible to 
match the infant's birth record and the mother's. We matched using the mother's first name, last name, exact date of birth, and state of birth. Of all the births that took place between 1989 and 2001 to mothers said to have been born in California in the relevant interval, we were able to match 81 percent. ${ }^{4}$ For a subset of these mother's who were born between 1970 and 1974, we can also use information about the mother's mother (the grandmother) to identify mother's who are siblings. We do this by matching the grandmother's name, age, state of birth, and race across birth certificates. Note that the exact date of birth of the mother is only recorded starting in 1989, and before that, the birth certificates record only the mother's (grandmother's) two-digit age. ${ }^{5}$ Our final sample includes 648,206 births.

We have used Census data to ask whether our matched data reproduces the actual structure of families in California over the relevant period. In our data, the distribution of numbers of children born between 1989 and 2001 to mothers who were born between 1970 and 1974 is: 51.9 percent have one child, 34.1 percent have two children, 10.8 percent have 3 children, and the rest have more. In the 2000 Census, mothers who were 26-30 years old and lived in California in 2000 had the following distribution of children 0 to 11 years old: 46.5 percent one child, 36.5 percent two children, 11.9 percent 3 children. Hence, these distributions are quite similar suggesting that we are doing a good job matching siblings in the 1989 to 2000 data.

If we look at the match of mothers to grandmothers, we find that 70 percent of the time, there is only one daughter matched, 15 percent of the time there are two daughters matched, and 6 percent of the time there are three daughters matched. If we use the 1980 Census to examine the number of children born between 1970 and 1974 to women born in California who were 12 to 45 in 1970, we

\footnotetext{
${ }^{4}$ The main matching problems were children from the later sample who could be linked to more than one mother in the earlier sample (i.e. common names) and children whose mothers were reported to have been born outside California but for whom a California birth record appeared to exist. The match rate is somewhat higher for whites and better educated people, but does not vary greatly across groups or counties. For example, for whites, we were able to locate 81.5 percent of the matches that should have been in the data, while for blacks we located 73.5 percent. Among women with more than 12 years of education, we located 83 percent of the matches while for women with exactly 12 years we located 79.4 percent. The county with the lowest match rate was Los Angeles, where 77.7 percent of potential matches were located, while the highest match rate was in tiny Alpine county where 85.7 percent of potential matches were located.

${ }^{5}$ We use race in this part because the recording of grandmother's race should be relatively stable between 1970 and 1974. In contrast, the way the mother's race was recorded on her birth certificate in 1970 may not be the same as the way her race is recorded on her child's birth certificate in 1989, for example, and having the exact date of birth makes matching mother's to children quite accurate even without race. We drop individuals for whom grandmother's name, age, state of birth, and race are missing. Of the linked grandmothers, 5899 grandmothers appear to have more than 20 grandchildren, and we drop them. We also drop individuals whose grandmother's hospital location could not be matched
} 
find that 88 percent had only one daughter, 11.1 percent had 2 daughters, and few had more than two daughters born in that short time interval. Comparing these two distributions suggests that they are not too different.

Before 1989, the birth certificate data includes the hospital of delivery, but very little by way of potential measures of socioeconomic status beyond race and age at the birth. Hence, we use the median income and poverty rate of the zip code of the hospital where delivery took place as a measure of the socioeconomic status of mothers at the time of the birth. If we think of there being grandmothers, mothers, and children in our data set, we have two potential measures of the mother's status: One taken at the time of her own birth, and one taken at the time of her child's birth.

After 1989, the data includes both the zip code of delivery and zip code of residence so it is possible to investigate the correlations between income/poverty in the two locations. Appendix Table 1 shows the results of this exercise. The correlations are strongly positive and statistically significant, but around .5 indicating that conditions in the hospital zip code are a noisy proxy for conditions in the zip code of residence. In most of our regression models, we divide people by quartile of zip code income or poverty, so it is of interest to see whether there is any systematic tendency for women living in high poverty zip codes to deliver in lower poverty ones or vice-versa. The second half of Table 1 shows that there is no such tendency: Fourty-five percent of mothers deliver in a zip code that has a poverty level similar to the poverty level in the area where they reside (that is, they locate on the diagonal in the table); 28 percent deliver in a better place than they reside, and 27 percent deliver in a worse place.

Appendix Table 2 shows how far the center of the zip code of residence is from the center of the zip code of the delivery. According to this measure, half the sample lives within 5.5 miles of the hospital, while 75 percent live within 10 miles. We have re-estimated our models excluding people who lived more than 10 miles from the hospital of delivery and found that this did not substantively change our results.

Figure 1 plots the birth weights of children born between 1989 and 2001 against the birth weights of their mothers, by income level. The plot begins at 1,500 grams because there are virtually no mothers with birth weights less than 1,500 grams in our sample. There is a clear break at 2,500 grams, the threshold below which infants are considered to be "low birth weight". Among 
mothers who were over 2,500 grams at birth, there is a clear positive relationship between the birth weights of mothers and their children. Equally striking however, is that when we divide the sample in three parts according to the median income in the mother's hospital's zip code, babies whose mothers were born into the highest income zip codes (line with circles) have higher birth weights than babies whose mothers were born into lowest income zip codes (line with triangles) regardless of their mother's initial birth weight. (The line for the middle-income group is in between the two lines, and it is not shown to make the graph easier to read). The gap is relatively small in the group with mothers over 2,500 grams, but quite large in the group whose mothers were low birth weight. Hence, the graph suggests the possibility of an interactive effect between maternal poverty and maternal low birth weight in the production of child birth weight.

Table 1 shows summary statistics. The mean birth weight for mothers born between 1970 and 1974 is 3,268, while for children born between 1989 and 2001 it is 3,387. The probability of low birth weight declined only slightly, from 6.3 percent to 6 percent. If we divide the sample by race, blacks have lower average birth weights than whites, but this appears to be largely due to the much higher incidence of low birth weight among blacks. The probability of low birth weight is 12 percent for blacks in both the earlier cohort and in the later.

As expected, children born in poor neighborhoods have worse birth outcomes, but the relationship between SES and birth outcomes is nonlinear. While the first three quartiles of the poverty distribution appear to be roughly equivalent, the last quartile (highest poverty) has more births with low birth weight. For example, for mothers born between 1970 and 1974, the probability of low birth weight is about 6 to 6.2 percent for the first three quartiles, and 7.2 precent (about 20 percent more) for the last quartile. Similarly, for children born between 1989 and 2001, the

probability of low birth weight is about 5.6 to 5.9 percent for the first three quartiles, and 7.0 percent (about 25 percent more) for the last quartile.

\section{A Simple Model and Methods}

A simple way to think about intergenerational transmission is as follows. Let (1) $\mathrm{BW}_{2}=\mathrm{bBW}_{1}+(1-\mathrm{b}) \mathrm{X}_{1}+\mathrm{e}_{2}$, where BW is birth weight, the subscript 2 represents the second generation, the subscript 1 represents the first generation, $\mathrm{X}$ is all other characteristics of generation 1 that affect generation 
two's birth weight, and $\mathrm{e}_{2}$ is a random shock. In this formulation, $\mathrm{BW}_{1}$ controls for all of the factors that affected the mother's birth weight, while $\mathrm{X}$ will include everything else, including the genetic heritage of the father and additional characteristics of the mother that did not affect her own birth weight such as her socioeconomic status after birth. If $E\left(B W_{1}\right)=E\left(B W_{2}\right)$, then

(2) $\operatorname{Cov}\left(\mathrm{BW}_{1}, \mathrm{BW}_{2}\right)=\mathrm{b}^{*} \operatorname{Var}\left(\mathrm{BW}_{1}\right)+(1-\mathrm{b}) \operatorname{Cov}\left(\mathrm{BW}_{1}, \mathrm{X}_{1}\right)$.

Evidently, we do not observe all of the characteristics of mothers (including the characteristics of the fathers they choose) that might be correlated with the child's birth weight. Hence, we first estimate (1) including only the mother's birth weight and controls for the infant's sex, the mother's race, and year effects to account for trends in birth weight over time. Equation (2) implies that by ignoring $\mathrm{X}$ variables that might be correlated with birth weight, this specification yields an upper bound estimate of the extent to which birth weight (or low birth weight) is passed from mother to child. To the extent that this estimate is biased upward by omitted variables, one would expect the estimated coefficient to fall as controls are added to the model.

We test this hypothesis by re-estimating (1) including grandmother fixed effects. Mother fixed effects would absorb the effects of both maternal birth weight and any constant X variables (such as longer run measures of maternal socioeconomic status). In contrast, the addition of grandmother fixed effects allows us to estimate the effect of maternal birth weight, conditional on the fact that mothers who are sisters have at least one and generally two common parents. The addition of these fixed effects offers a powerful way to control for some elements of the mother's background which are not captured in her own birth weight (e.g. the family environment when she was growing up). A comparison of the models with and without grandmother fixed effects tells us how much of the observed correlation in birth weights is due to all the determinants of health that common among siblings. We next add 1970 median income in the zip code where the mother was delivered in an attempt to control for factors that may have changed within families.

Finally, we estimate (1) including both grandmother fixed effects and mother characteristics such as age, education and parity, as well as fixed effects for the zip code where the mother delivered. These variables are likely to themselves be influenced by the mother's birth weight and family background. However, mother's birth weight, grandmother fixed effects, and mother's income at the time of her own birth (our proxies for family background) are already included in the model. Hence, a comparison of this model with the previous ones may show how much of the inter- 
generational correlation can be accounted for by the mother's trajectory after her own birth as well as by contemporaneous factors that are captured by the zip code fixed effects. Importantly, the mother's zip code at the time of the child's birth is likely to be correlated with the socio-economic status (and hence with the birth weight) of the father and so offers a partial control for this potentially important class of omitted variables. If we can drive the correlation between mother and child's birth weight down significantly by adding measures of the mother's status at the time of the child's birth, this would suggest that it is possible to intervene at this point to break the intergenerational cycle of low birth weight. Of course, even if our set of controls is quite rich, they are by no means perfect and we can not completely rule out the possibility of omitted variable bias.

A potentially important limitation of (1) is that it does not allow for an interaction between $\mathrm{BW}_{1}$ and $\mathrm{X}_{1}$. An interactive model will allow us to test more directly for the extent to which intergenerational transmission is mitigated by $\mathrm{X}$ variables. We wish to estimate a model akin to: $\mathrm{BW}_{2}=$ $a_{1} B W 1+a_{2} X_{1}+a_{3} B W_{1} * X_{1}+e_{2}$. What we actually estimate is more flexible, in that we do not require $\mathrm{X}_{1}$ to have a linear effect. Specifically, we estimate:

(3) $\mathrm{BW}_{2}=\mathrm{a}_{1} \mathrm{X}_{1}{ }^{\prime}+\mathrm{a}_{2} \mathrm{BW}_{1} * \mathrm{X}_{1}{ }^{\prime}+\mathrm{e}_{2}$,

where $\mathrm{X}_{1}$ ' is a vector of indicators for quartiles of the income distribution, or of the poverty distribution.

We implement (3) in two ways. First, we use the grandmother's socioeconomic status at the time of the mother's birth as a measure of $\mathrm{X}_{1}$ ', as measured by the median income or the poverty rate in the zip code of the mother's own delivery. This measure of $\mathrm{X}_{1}$ ' is predetermined, and not alterable by subsequent choices of the mother. Hence, we prefer this specification on conceptual grounds. However, because we only observe zip code of residence (which we believe is a better proxy for the income of the mother than zip code of delivery) after 1989, we also estimate a second set of models using the mother's status at the time of the child's birth as our measure of $\mathrm{X}_{1}$ '.

As Solon (1999) points out, the underlying model of intergenerational transmission also has implications for relationships between siblings. In the model above, let the subscript 3 represent the sister of person 2. That is, both 2 and 3 are daughters of person 1 . Then

(3) $\operatorname{Cov}\left(\mathrm{BW}_{3}, \mathrm{BW}_{2}\right)=\mathrm{b}^{2} * \operatorname{Var}\left(\mathrm{BW}_{1}\right)+2 \mathrm{~b}(1-\mathrm{b}) \operatorname{Cov}\left(\mathrm{BW}_{1}, \mathrm{X}_{1}\right)+(1-\mathrm{b})^{2} * \operatorname{Var}\left(\mathrm{X}_{1}\right)$.

This will exceed the $\operatorname{Cov}\left(\mathrm{BW}_{1}, \mathrm{BW}_{2}\right)$ to the extent that the $\mathrm{X}$ variables are an important determinant of the child's birth weight, and to the extent that these variables co-vary with maternal birth weight. 
If there are no $\mathrm{X}$ factors affecting child birth weight then the correlation in birth weight between siblings will be smaller than the correlations between mothers and their children $\left(\mathrm{b}^{2} * \operatorname{Var}\left(\mathrm{BW}_{1}\right)<\right.$ $\left.\mathrm{b} * \operatorname{Var}\left(\mathrm{BW}_{1}\right)\right)$. On average, each sibling gets 50 percent of his or her genetic material from their mother, but different siblings receive different subsets of their mother's genetic stock. These differences in the genetic stock inherited from the mother tend to be offset by the sibling's shared maternal characteristics, such as maternal nutrition, income, or education. As we will show below, correlations between siblings are actually much higher than correlations between mothers and their children, suggesting that such $\mathrm{X}$ variables are very important. ${ }^{6}$

\section{Results}

\subsection{Correlations among Siblings}

We begin the exploration of the data by estimating simple correlations between the birth weights of mothers and children, between the birth weights of siblings in the mother's generation, and between the birth weights of siblings in the child's generation. A comparison of these quantities will shed light on the extent to which correlations in birth weight change between generations and with social class, and hence on the extent to which social factors may be important.

Table 2 shows correlations in low birth weight, birth weight, and log birth weight. The first two columns have a straightforward interpretation. The latter column downweights the potential influence of outliers in birth weight. The first row shows that there is little correlation between the birth weights of two randomly chosen babies born into the same hospital, even though one might expect these babies to have more similar attributes than babies born into completely different areas.

The second panel indicates that correlations between siblings in the "child generation", i.e. the generation born between 1989 to 2001 are much higher, .28 for low birth weight and .45 for birth weight. However, these correlations are not directly comparable with those of the mother's generation, because the sample of mothers that we have are sisters who were born less than five years apart. The third panel of Table 2 imposes these restrictions and shows that in this sub-sample

6 We can also compute the covariance in birth weights between cousins: $\operatorname{Cov}\left(\mathrm{BW}_{4}, \mathrm{BW}_{5}\right)=\mathrm{b}^{2} * \operatorname{Var}\left(\mathrm{BW}_{2}\right)+$ $\mathrm{b}(1-\mathrm{b}) \operatorname{Cov}\left(\mathrm{BW}_{2}, \mathrm{X}_{3}\right)+\mathrm{b}(1-\mathrm{b}) \operatorname{Cov}\left(\mathrm{BW}_{3}, \mathrm{X}_{2}\right)+(1-\mathrm{b})^{2} * \operatorname{Cov}\left(\mathrm{X}_{2}, \mathrm{X}_{3}\right)$, where subscript 4 indicates the child of person 2, and subscript 5 indicates the child of person 3 . This expression indicates that correlations in the birth weights of cousins will generally be less than the correlation in birth weights of siblings because the birth weight of person 2 is less highly correlated with the other characteristics of person 3 than with person 2's own characteristics, etc. We have verified that this is the case in these data. 
of sisters born relatively close together, inter-generational correlations in birth weight are much higher. We have also estimated these models excluding children from the 1989-2001 cohort who were less than 1,500 grams at birth, on the grounds that such children would not have survived in earlier generations. However, this change made little difference.

Correlations in the mothers' generation are shown in the fourth panel of Table 2. It is striking that while the correlation in birth weights is quite similar in the two generations, the correlation in the incidence of low birth weight is smaller in the child generation. In keeping with the model outlined above, the decline in these correlations between generations may suggest that the variation in other determinants of low birth weight (apart from the mother's birth weight) decreased over time. It is difficult to point to one specific factor, but improved access to health care may have played a role. The fact that the mother-child correlations shown in the last panel are so much lower than either set of sibling correlations also suggests the importance of factors in addition to maternal birth weight. Thus, this simple table indicates that inter-generational correlations in low birth weight are unlikely to be purely genetic.

Table 2 also explores the hypothesis that correlations in low birth weight are higher among children born to poor mothers. In all panels, poverty is defined using the fraction of households in poverty in the mother's zip code and time of birth. Panels 2 and 3 suggest that there is little relationship between the correlations between siblings and the poverty level in the zip code where the mother was born. But the last two panels of the table break out the correlations between mothers who are sisters by the poverty of the mother's zip code of birth. The correlation in low birth weight between sisters is higher if they were born in high poverty zip codes, and the size of the difference is large in percentage terms: The correlation in the probability of low birth weight rises 50 percent if the women were born into high poverty zip codes.

\subsection{Intergeneration correlations in birth weight}

To what extent are health shocks transmitted across generations? Table 3 presents estimates of the effects of maternal SES and maternal birth weight on the child's birth weight (Equation 1). Because our preferred models include grandmother fixed effects, identification comes from the comparison of the birth outcomes of sisters.

We present estimates for three alternative models: a regression of an indicator equal to one if 
the child is low birth weight on an indicator equal to one if the mother is low birth weight (first row); a regression of child's birth weight on mother's birth weight (second row); and a regression of log of child's birth weight on log of mother's birth weight (third row). All three models are potentially interesting, and capture different aspects of the intergenerational transmission of health. The models in the Table are estimated using the sample of children whose mothers could be linked to their grandmother's (i.e. whose mothers were born between 1970 and 1974). ${ }^{7}$

The first column shows estimates from models without controls. The probability that a child is low birth weight is 3.8 percentage points higher if her mother is also low birth weight. This is a large effect, given that the average probability of low birth weight is 6.0. In percentage terms, this effect is 63 percent of the baseline. The second column shows estimates that include only the baby's gender, mother's race, and year of birth effects. The coefficient drops to 3.2 percentage points which is mainly due to controlling for race.

Column 3 shows models including grandmother fixed effects. This specification uses within family differences among siblings as the only source of variation, and therefore controls for many permanent unobserved factors that might vary across families. Although the standard error triples, the point estimate on maternal low birth weight declines only marginally to 2.9 percentage points and remains highly significant. In percentage terms, this effect is 46 percent of the average probability of low birth weight. Ideally, one would like to control for at least some of the timevarying factors that may have contributed to low birth weight status in one of the sisters but not in the other. In column 4 we include SES at the time of the mother's birth as measured by poverty in her hospital of birth zip code, but this has little effect on the point estimate.

The two remaining columns show the effects of sequentially adding the following variables to the model: maternal age, education and parity; and fixed effects for maternal zip code at the time of the child's birth. These additional controls are potentially endogenous, as discussed above. Still, it is interesting to note that the point estimates in column 5 and 6 do not change relative to column 4.

A qualitatively similar pattern emerges when we look at birth weight and log of birth weight in rows 2 and 3, though adding grandmother fixed effects has a smaller impact on the point estimates on mother's birth weight. Row 2 of column 3 indicates that a 100 gram increase in mother's birth

\footnotetext{
${ }^{7}$ Models with grandmother fixed effects can only be estimated using this sub-sample, although very similar estimates were obtained using the full sample.
} 
weight results in a 20 gram increase in child's birth weight, after controlling for grandmother fixed effects. Row 3 indicates that this amounts to an elasticity of 17 percent.

One remarkable feature of Table 3 is that it shows that the correlation between mother and child birth weights (or in the incidence of low birth weight) is remarkably stable once we control for grandmother fixed effects. It is particularly striking that it is robust to current zip code of residence fixed effects which partially control for the mother's current economic status. Of course, it is certainly possible that omitted factors are driving our results. However, the stability of the coefficients as we move from column 3 to column 6 lends some credibility to the idea that maternal birth weight actually affects child birth weight, and that the estimates in the Table do not reflect only omitted factors. In other words, having a mother who is low birth weight appears to have an impact on the probability that the child is low birth weight independent of genetic factors or other permanent indicators of the background of the mother. This is consistent with the fetal programming hypothesis discussed above.

In the middle and bottom panel, we present estimates for whites and blacks separately. The middle panel shows that for whites, adding grandmother fixed effects reduces the estimated effect of low birth weight of the mother on low birth weight of the child from 2.7 percentage points to 2.1 percentage points, but the addition of other covariates has little effect. For blacks, the inclusion of grandmother fixed effects results in a larger decline in the estimated intergenerational transmission of health: the coefficient for the low birth weight model falls from 5.4 percentage points to 4.1 percentage points. Given the larger baseline incidence of low birth weight for blacks, both estimates imply a roughly 25 percent decline in the estimated coefficient when grandmother fixed effects are added.

The low birth weight models indicate that the coefficient on maternal low birth weight is twice as large for blacks as for whites, indicating that the intergenerational transmission of low birth weight is much stronger for blacks than for whites. Specifically, in models that control for grandmother fixed effects, a white child with a mother who is low birth weight is 2 percent more likely to be low birth weight, while for blacks the equivalent figure is 4 percent. In contrast, the effect of a continuous measure of maternal birth weight on child birth weight is very similar for blacks and whites: For each 10 grams increase in maternal birth weight, child birth weight rises by 1.9 grams. The fact that intergenerational correlations in low birth weight are more sensitive to an 
indicator of SES (in this case race) than intergenerational correlations in birth weight is a pattern that we find throughout the paper, and suggests that we might find significant interactions between low birth weight and more direct measures of SES, a question we investigate in the next section.

\subsection{SES Interactions.}

Tables 4 and 5 ask whether the intergenerational transmission of birth weight uncovered in Table 3 is stronger depending on socio-economic status. As discussed above, there are two possible measures of the mother's SES. One is taken at the time the mother was born, and is the income or poverty level in the zip code of the hospital where she was delivered. The second is taken at the time of the child's birth and is the income or poverty level in the mother's zip code of residence. Table 4 shows models estimated using the first measure(s) while Table 5 shows models estimated using the second. Because Table 2 showed a non-linear effect of income and poverty on birth outcomes, we focus on whether the mother was in the highest poverty or lowest income quartile of the distribution. Indicators for being in one of these quartiles are interacted with maternal birth weight in order to see whether intergenerational correlations in birth weight differ with SES. All models include the SES main effects as well as the basic controls of the child's race, sex and year of birth. Models in the even numbered columns also include grandmother fixed effects.

The main effects shown in Table 4 indicate that, as expected, that socio economic status is correlated with birth weight. For example, conditional on grandmother fixed effects, the incidence of child low birth weight is about a 0.4 percentage points higher if the mother was born into a high poverty zip code, and 0.1 percentage point lower if the mother is born in a low income zip code (column 2). These differences represent a large increase given that the baseline incidence of low birth weight is only six percent. In contrast, average birth weight is only 25 to 30 grams lower if the mother is born in poor zip codes, and these estimates are only marginally significant. Compare this with the baseline, which is 3268 grams.

The results in Table 4 are interesting for two reasons. First, they confirm that our measure of SES at the time of the mother's birth has some signal, even if it is a noisy proxy for income in the mother's zip code of residence. Second, low birth weight is much more sensitive to SES than birth weight above some cutoff, which is consistent with Turkheimer's model. The same is true if we look at log birth weight (not shown). 
Turning to the interactions, column 1 shows that there might be an interaction between maternal SES at birth and maternal birth weight in models of low birth weight, although our estimates are not precise. Children born to a low birth weight mother are more likely to be low birth weight themselves (as we saw in Table 3), and the point estimate indicates that the effect is larger if the mother was also born into a high poverty zip code. A similar result is obtained if we look at the income interaction in the bottom panel. But column 2 shows that these results are not robust to the inclusion of grandmother fixed effects. Overall the evidence about interaction effects in Table 4 is not conclusive, and we cannot reject the hypothesis that the correlation between mother and child in low birth weight and birth weight is the same across SES groups.

One problem with Table 4 is that the variation in SES at birth among siblings is rather limited. A second problem is that income in the zip code of residence at the time of the mother's own birth is less accurately measured than income in the zip code of residence at the time of the child's birth because, as discussed above, we did not know zip code of residence in the early years of the Vital Statistics data and we proxy for it using the zip code of the hospital of delivery. Table 5 shows similar models estimated using poverty or income in the mother's zip code of residence at the time of the child's birth rather than measures of her SES at the time of her own birth. These are measures of her current economic status, though they are correlated with her past status. These measures show more between-sibling variation than the longer-term measure of status used in Table 4.

Table 5 is organized in the same way as Table 4. Estimates using low birth weight as the dependent variable appear in columns 1 and 2. These estimates show a sharp gradient in the interaction terms, and the differences in the effect of low birth weight between SES groups remain statistically significant even after the introduction of grandmother fixed effects. In terms of magnitudes, the estimates in Table 5 suggest that children born in poor households are .045 percentage points more likely to be low birth weight if their mothers were low birth weight. Among non-poor households the comparable estimate is .024. Hence, poverty raises the probability that low birth weight is transmitted by 88 percent!

One possible interpretation of the contrast between the results in Tables 4 and 5 is that measures of the mother's SES at the time of the child's birth are more relevant to predicting whether or not the child will be low birth weight than measures taken at the time of the mother's birth. An 
alternative interpretation is that the results are stronger because income in the zip code of residence is more accurately measured at the time of delivery and there simply is more variation in SES at delivery than in SES at birth.

Using SES measured at the time of the child's birth also allowed us to replicate Dalton and Conley's model by including mother fixed effects. Model's with mother fixed effects focus on short-term changes in the economic status of the mother between the births of her children. We have estimated these models and find that there is no significant interaction between maternal low birth weight and maternal poverty (or income). That is, in mother fixed effects models, the effect of maternal low birth weight is the same whether the child was born in a low poverty or a high poverty area. (Alternatively, the effect of income is the same whether or not the parent is low birth weight). Hence, we find little evidence that short-term variations in a mother's income have an impact on the birth weight of her children. These results are available on request.

The interpretation of models using changes in the mother's economic status (as of the time of the child's birth) require some care because it is possible that a mother's economic status is affected by her health. For example, if a mother got sick and then became poor, moved to a lower income neighborhood, and subsequently had a low birth weight baby, then the estimated effect of the socioeconomic status would be biased away from zero because it would capture part of the effect of unobserved sickness. However, in our case, this potential bias makes our finding of no effect of current economic status stronger.

\subsection{Long-Run Effects of birth weight on Socio-Economic Status}

In the preceeding tables, we showed that low birth weight is transmitted across generations, that poverty has an independent effect on the incidence of low birth weight, and that poverty and low birth weight interact to produce low birth weight in the next generation. An important remaining question is whether low birth weight in turn, affects future SES. In addressing this question, we also explore one possible channel that might explain the correlations uncovered in Table 3. In previous work we argue that the SES of the mother affects the child's birth weight (Currie and Moretti, 2003). If it turns out that being born low birth weight affects a mother's SES later in life, this would suggest that intergenerational correlations in health status were related to the intergenerational transmission of poverty. 
This question is addressed in Table 6 which shows models using the mother's socioeconomic status at the time of the child's birth as the dependent variable. These SES measures are regressed on the mother's own birth weight, as well as on the measure of maternal SES at the time of her own birth (i.e. the grandmother's SES). The SES measure at the time of the child's birth is the median family income in the mother's zip code of residence as of the 1990 Census (converted to real \$1970). The measure of SES at the time of the mother's birth is the median family income in the hospital where the mother was born, as of the 1970 Census.

Table 6 shows that there is a strong correlation between SES at the time of the mother's own birth and her SES at the time of her child's birth. But the mother's birth weight or low birth weight has an independent predictive effect (column 1).

Notably, the addition of grandmother fixed effects causes the effect of low birth weight to be reduced, but it remains highly statistically significant though relatively small. That is, of two sisters born in the same type of neighborhood, the one with lower birth weight is more likely to live in a lower income zip code when she gives birth to her own child many years later. The magnitude of the effect is non-trivial. For example, being low birth weight is associated with a loss of \$105 in future income, on average, on a baseline income of 10,096 \$1970. (column 3). Hence, these models show that low birth weight is a significant predictor of future status in our models, even conditional on the inclusion of grandmother fixed effects. This result is consistent with Smith (2005) who finds that an adult retrospective report of poor health in childhood is a significant predictor of adult education and income even in sibling fixed effects models. Birth weight can be viewed as a narrow, but more accurately measured indicator of health.

The models in Table 6 can also be interpreted as typical "Solon” regressions of child income on parent's income, except that income is measured at the zip code rather than at the individual level, income is measured at the time of birth for both parent and child, and income is not measured in quite the same way for mother and child (see, for example, Solon 1999). It is interesting to compare the coefficient on parent's income from these models to those that have appeared in the literature. The coefficient of .128 is likely to be an underestimate of the coefficient we would obtain if we had income in the zip code of residence for both mother and child: Recall that the correlation between income in the hospital of delivery and income in the hospital of residence is about .5. This suggests that the coefficient we would obtain using zip code of residence for both would be about 
.26 which is in the same range as many previous estimates of inter-generational correlations in income in the United States. The results are similar if we look at blacks and whites separately (columns 3 to 6 ).

The remaining sections of Table 3 explore the impact of birth income and birth weight on two other indicators of mother's SES at the time of her child's birth: Her education and her residence in a high poverty neighborhood. Education is the mother's self-reported education from the birth certificate. It is particularly interesting because--unlike the other outcome variables in the table--it is an individual-level measure. The grandmother fixed effects estimates suggest that being low birth weight increases the probability of living in a high poverty neighborhood (defined as one in the highest quartile of poverty rates) by about 3 percent relative to baseline, and that it reduces future educational attainment by about a tenth of a year.

Overall, we conclude that--whether we use individual level measures of SES such education or aggregate measures - our findings seem to support the notion that being born low birth weight has a non-trivial effect on socio-economic status later in life.

\subsection{SES Interactions.}

Table 6 indicates that being born low birth weight has a long run effect on later SES achievement. But does this effect vary across SES groups? In Table 7 we present estimates of models similar to the ones in Table 6, where we have added the interaction between low birth weight (or birth weight) and indicators for low and high SES. We measure SES using the median 1970 income of the zip code of the hospital of mother birth.

The first point to notice is that the main effects are all large and significant. For example, the estimates in columns 1 and 2 indicate that being born in the poorest quartile of zip codes is associated with a loss of $\$ 1,168$ to $\$ 1,322$ in average income later in life. Since this effect is measured in 1970 dollars, and represents about 10 percent of the average income in the sample, it is a large effect. Turning to the interactions, the estimates in column 1 and 2 suggest that being born low birth weight has an overall negative effect, but the negative effect is larger for those women who are born in poorer areas. Women who are born low birth weight and are from poor areas experience an additional average income loss of about $\$ 238$, which falls to $\$ 155$ when we include grandmother fixed effects. The corresponding loss for women who are born low birth weight but are from less 
disadvantaged areas is only \$147 (column 1) or \$93 when we include grandmother fixed effects. The gap appears larger for blacks than for whites (column 5 and 9). Similar results obtain when we look at the interaction between birth weight and SES. One additional gram in birth weight is associated with an average increase in income of \$.15 for women born in the low SES group, and \$.10 for women born in the high SES group (column 2). However, few of these differences are statistically significant. Similarly, when we examine interactions in models of education and residence in a high poverty zip code, we do not find statistically significant differences.

We have also estimated models pushing our specification further and allowing for four SES groups (defined using quartiles). The main effects are monotonically increasing in SES. For example, in models that include grandmother fixed effects the average future incomes of mothers born in the second, third and fourth quartiles of income are \$605, \$958, \$1493 higher than the average income of mothers born in the first income quartile. This is consistent with what Solon has shown on the intergenerational transmission of income. The interactions also show a monotonic pattern, with the strongest effects for lowest income quartile and the weaker effect for the highest income quartile, but these effects are not statistically significant.

\subsection{Limitations}

Our results are subject to several limitations given the crudeness of our measure of SES, and the lack of data on several important determinants of child birth weight. One of the most important problems is that because of data limitations, we measure the mother's SES at the time of her own birth using the zip code of the hospital of delivery, rather than the zip code of residence, which we view as a more accurate proxy for individual income. (As we have shown in Appendix tables A1 and A2, the two measures are highly but not perfectly correlated in the years were both measures are available.)

A second issue is that we are measuring SES at the zip code, rather than at the individual level. However, as Solon (1999) demonstrates, point-in-time measures of SES may be misleading, since there is a great deal of transitory variation in these measures. In contrast, place of residence is a less fleeting measure of status, and so may be more relevant for our investigation. To the extent that neighborhoods have their own effects on individuals, characteristics of zip code of residence may be regarded as measures of status that are of interest in their own right, as well as proxies for 
individual status. It is worth noting that in addition to median income and poverty in the zip code, we investigated additional SES measures including median property values and the fraction of adults who were high school dropouts or college graduates in a zip code. These alternatives yielded similar estimates to those described above.

A third source of potential bias is that we observe mother's birth weight but have little information about the father. As discussed above, the inclusion of fixed effects for the mother's current zip code of residence might be expected to partially mitigate this problem (if current zip code of residence is highly correlated with the father's birth weight and socio economic status). And we found that the addition of these controls had little impact on our estimates.

However, given reasonable assumptions, we may also be able to bound the extent of potential bias from this source. Suppose we modify equation (1) as follows (and ignore the other $X$ 's since we showed above that they have relatively little impact on the estimated coefficient on mother's birth weight):

(1)' $\mathrm{BW}_{2}=\mathrm{a}_{1} \mathrm{BW}_{\text {Mother }}+\mathrm{a}_{2} \mathrm{BW}_{\text {Father }}+\mathrm{e}$,

and suppose further that:

(4) $\mathrm{BW}_{\text {Father }}=\mathrm{cBW}_{\text {Mother }}+\mathrm{u}$.

If $\mathrm{a}_{1}=\mathrm{a}_{2}$, then the extent of the bias from omitting father birth weight depends on the parameter $\mathrm{c}$. If $c=1$ and we omit BWFather from (1)' then the estimated coefficient on BW $\mathrm{B}_{\text {Mother }}$ will equal $2 * \mathrm{a}_{1}$. If $\mathrm{c}=0$, then the estimated coefficient on $\mathrm{BW}_{\text {Mother }}$ will be unbiased. Positive assortative mating suggests that $0>\mathrm{C}>1$ so that the coefficient on $\mathrm{BW}_{\text {Mother }}$ captures some of the effect of the omitted father's birthweight. In fact, Cole (2000) finds that the correlation between mother's and father's heights is about .8. If the relationship between parents' birth weights is similar, then dividing the estimated coefficient on mother's birth weight by two provides a lower bound on the true effect of mother's birth weight on child birth weight independent of father's birth weight. On the other hand, if what we are interested in is the effect of the parent's endowments on the endowments of the children, then the fact that the mother's coefficient captures much of the effect of the father is perhaps a positive.

\section{Conclusions}

We show that there is a strong intergenerational correlation in birth weight which does not 
seem to be due to omitted variables—-women whose mothers were low birth weight are 50 percent more likely to be low birth weight themselves. This correlation persists when a rich set of controls including grandmother fixed effects and measures of income at the time of the mother's birth are added to the model. We also show that poverty of the mother has an independent effect on the incidence of low birth weight in the child and that there is an interaction between maternal low birth weight and poverty in the production of low birth weight in the child. Finally, we find that mothers who were low birth weight are more likely to live in a high poverty zip code and have less education at the time of their own child's birth many years later. These effects are highly statistically significant and present when we control for income at the time of the mother's birth as well as for grandmother fixed effects.

Together these findings suggest that intergenerational correlations in health could play a role in the intergenerational transmission of income. Parent's income affects child health, and health at birth affects future income. Although the estimated effects of low birth weight on future income, education, and poverty are modest it is important to note that low birth weight is only a crude measure of health at birth and that poor children tend to accumulate health insults as they age at a faster rate than rich children. Thus, the overall effect of health in childhood could be large.

Our paper provides evidence that there is a significant societal component to low birth weight, and rejects biological determinism in this important outcome. Interventions that target girls and successfully improve their socioeconomic status are likely to also improve the health outcomes of their children. Thus, successful early intervention programs may have intergenerational effects. 


\section{References}

Almond, Doug, Ken Chay and David Lee, “The Cost of Low Birth Weight”, Quarterly Journal of Economics, forthcoming.

Barker, David. “In Utero Programming of Chronic Disease,” Clinical Science, 95, 115-128, 1998.

Behrman, Jere and Mark Rosenzweig. “The Returns to Increasing Body Weight,” February 2001.

Breslau, N., J.E. DelDotto, G.G. Brown, S. Kumar, S. Ezhuthachan, K.G. Hufnagle, and E.L. Peterson. “A Gradient Relatioinship Between Low Birth Weight and IQ at Age 6 Years,” Archives of Pediatric and Adolescent Medicine, 148, 1994, 377-383.

Brooks-Gunn, Jeanne, Patricia Klebanov, and Greg Duncan. “Ethnic Differences in Children’s Intelligence Test Scores: Role of Economic Deprivation, Home Environment, and Maternal Characteristics,” Child Development, 67, 1996, 396-408.

Case, Anne, Angela Fertig and Christina Paxson. "The Lasting Impact of Childhood Health and Circumstance," Center for Health and Well Being, Woodrow Wilson School, Princeton University, April 27, 2004.

Case, Anne, Darren Lubotsky and Christina Paxson. "Economic Status and Health in Childhood: The Origins of the Gradient,” American Economic Review, 92 \#5, 2002, 1308-1334.

Caspi, Avshalom, K. Sugden, Terri E. Moffitt, A. Taylor, I. Craig, H. Harrington, J, McClay, J. Mill, J. Martin, A. Braithwaite, R. Poulton. "Influence of Life Stress on Depression: Moderation by a Polymorphism in the 5-HTT Gene,” Science, 2003, 301, 386-399.

Charles, Kerwin and Eric Hurst. "The Correlation of Wealth Across Generations," Journal of Political Economy, December 2003.

Cole, T.J. “Galton’s Midparent Height Revisited,” Annals of Human Biology, July-august 27 \#4, 2000, 401-405.

Collins, James W, Shou-Yien Wu, and Richard David. "Differing Intergenerational Birth Weights Among the Descendants of U.S.-born and Foreign-born Whites and African Americans in Illinois," American Journal of Epidemiology, 155 \#3, 210-216.

Collins, J.W. and R.J. David. “The Differential Effect of Traditional Risk Factors on Infant Birth Weight Among Blacks and Whites in Chicago,” American Journal of Public Health, 80 \#6, 1990, 679-681.

Conley, Dalton and Neil Bennett. "Is Biology Destiny? Birth Weight and Life Chances,” American Sociological Review, 65, 2000, 458-467. 
Conley, Dalton and Neil Bennett. "Birth Weight and Income: Interactions Across Generations," Journal of Health and Social Behavior, 42, Dec. 2001, 450-465

Conley, Dalton, Kate Strully, and Neil Bennett. “The Starting Gate: Birth Weight and Life Chances,” (Berkeley: University of California Press) 2003

Coutinho, Russell, Richard David, and James Collins. "Relation of Parental Birth Weights to Infant Birth Weight Among African Americans and Whites in Illinois," American Journal of Epidemiology, 146 \#10, 1997, 804-809.

Currie, Janet and Rosemary Hyson. "Is the Impact of Health Shocks Cushioned by Socioeconomic Status? The Case of Low Birth Weight,” American Economic Review, 2, May 1996, 19-22.

Currie, Janet and Bridgit Madrian. "Health, Health Insurance, and the Labor Market,” in Orley Ashenfelter and David Card (eds.) Handbook of Labor Economics, v3, 3309-3415 (Amsterdam: North Holland) 1999.

Currie, Janet and Mark Stabile. "Socioeconomic Status and Health: Why is the Relationship Stronger for Older Children?” American Economics Review, 93 \#5, December 2003, 1813-1823.

Drake, A.J. and B.R. Walker. "The Intergenerational Effects of Fetal Programming: Non-Genomic Mechanisms for the Inheritance of Low Birth Weight and Cardiovascular Risk," Journal of Endocrinology, 180, 2004, 1-16.

Duncan, Greg and Deborah Laren. "Neighborhood and Family Correlates of Low Birth Weight: Prelimnary Results on Births to Black Women from the PSID Geocode File,” (Ann Arbor MI: Survey Research Center), 1990.

Emanuel, Irvin, Haroula Filakti, Eva Alberman, Stephen Evans. "Intergenerational studies of human birth weight from the 1958 birth cohort. 1. Evidence for a multigenerational effect," British Journal of Obstetrics and Gynaecology, 99, Jan 1992, 67-74.

Eriksson, Tor, Bernt Bratsberg, and Oddbjorn Raaum. "Earnings Persistence Across Generations: Transmission Through Health?” paper presented at the Society for Labor Economists meetings, San Francisco, June 2005.

Floud, Roderick, Kenneth Wachter, and Annabel Gregory. Height, Health, and History (Cambridge: Cambridge University Press) 1990.

Fogel, Robert, W. "Economic Growth, Population Theory, and Physiology: The Bearing of LongTerm Processes on the Making of Economic Policy,” The American Economic Review, Vol. 84, No. 3 (Jun., 1994), pp. 369-395.

Gortmaker, Stephen. "Poverty and Infant Mortality in the United States,” American Sociological Review, 44, 1979, 280-297. 
Grossman, Michael. "The Human Capital Model," in The Handbook of Health Economics, Anthony Culyer and Joseph P. Newhouse (eds.) (Amsterdam: North Holland) 2000.

Herrnstein, Richard and Charles Murray. The Bell Curve: Intelligence and Class Structure in American Life (New York: The Free Press) 1994.

Huxley, Rachel. et al. Christopher G. Owen, Peter H. Whincup, Derek G. Cook, Sam Colman, Rory Collins " Birth Weight and Subsequent Cholesterol Levels: Exploration of the "Fetal Origins" Hypothesis,” Journal of the American Medical Association, Dec. 8, 2004, vol 292: pp 2755-2764.

Kalter, Harold. "Teratology in the $20^{\text {th }}$ Century: Environmental Causes of Congenital Malformations in Humans and How They Were Established," Neurotoxicology and Teratology, v25 \#2, MarchApril 2003, 131-282, special issue.

Lumey, L.H. "Decreased Birth Weights in Infants After Maternal in Utero Exposure to the Dutch Famine of 1944-1945," 6, 1992, 240-253.

Moffitt, Terrie E., Avshalom Caspi, Michael Rutter. "Strategy for Investigating Interactions Between Measured Genes and Measured Environments," Archives of General Psychiatry, November 2004.

Smith, James P. “The Impact of SES on Health over the Life-Course,” xerox, RAND, March 2005.

Solon, Gary. "Intergenerational Mobility in the Labor Market," Chapter 29 in Handbook of Labor Economics, volume 3A, Orley Ashenfelter and David Card (ed.) (Amsterdam: North Holland) 1999.

Starfield, Barbara, S. Shapiro, J. Weiss, K. Liang, K. Ra, D. Paige, and X. Wang. "Race, Family Income and Low Birth Weight,” American Journal of Epidemiology, 134, 1991, 1167-1174.

Stein, A.D. and L.H. Lumey. "The Relationship Between Maternal and Offspring Birth Weights after Maternal Prenatal Famine Exposure: The Dutch Famine Birth Cohort Study,” Human Biology, 72, 2000, 641-654.

Turkheimer, Eric, Andreana Haley, Mary Waldron, Brian D’Onofrio, and Irving Gottesman. "Socioeconomic Status Modifies Heritability of IQ in Young Children," Psychological Science, v 14 \#6, Nov. 2003, 623-628.

Yeh, T.F., Y. Lin, H.C. Lin, C.C. Huang, W.S. Hsieh, C.H. Lin, C.H. Tsai. "Outcomes at School Age after Postnatal Dexamethasone Therapy for Lung Disease of Prematurity,” New England Journal of Medicine, 350, March 25, 2004, 1304-1313. 
Birth Weight

Mothers born 1970-1974

All

White

Black

1st poverty quartile (low poverty)

2nd poverty quartile (medium low poverty)

3rd poverty quartile (medium high poverty)

4th poverty quartile (high poverty)
3268

3295

3077

3272

3276

3274

3238
Low Birth Weight

0.063

0.056

0.120

0.062

0.060

0.060

0.072

All Children 1989-2001

All

3387

0.060

White

3420

0.053

Black

3143

0.120

1st poverty quartile (low poverty)

3410

0.056

2nd poverty quartile (medium low poverty)

3394

0.059

3rd poverty quartile (medium high poverty)

3399

0.057

4th poverty quartile (high poverty)

3344

0.070 
Table 2: Correlations in Birth Weight Measures, by SES at time of Mother's Birth

\begin{tabular}{|c|c|c|c|}
\hline & $\begin{array}{c}\text { Low } \\
\text { Birth Weight }\end{array}$ & $\begin{array}{c}\text { Birth } \\
\text { Weight }\end{array}$ & $\begin{array}{c}\text { Log } \\
\text { Birth Weight }\end{array}$ \\
\hline \multicolumn{4}{|l|}{ Correlation between: } \\
\hline $\begin{array}{l}\text { (1) Two randomly chosen babies born } \\
\text { in the same hospital }\end{array}$ & -0.02 & 0.03 & 0.05 \\
\hline (2) Two randomly chosen siblinqs - 1989-2001 & 0.28 & 0.45 & 0.42 \\
\hline 1st poverty quartile (low poverty) & 0.29 & 0.47 & 0.45 \\
\hline 2nd poverty quartile (medium low poverty) & 0.28 & 0.45 & 0.44 \\
\hline 3rd poverty quartile (medium high poverty) & 0.27 & 0.44 & 0.41 \\
\hline 4th poverty quartile (high poverty) & 0.27 & 0.43 & 0.39 \\
\hline \multicolumn{4}{|l|}{ (3) Two randomly chosen sisters, born $<=4$ years apart } \\
\hline 1989-2001 cohort & 0.42 & 0.56 & 0.58 \\
\hline 1st poverty quartile (low poverty) & 0.46 & 0.49 & 0.62 \\
\hline 2nd poverty quartile (medium low poverty) & 0.39 & 0.56 & 0.61 \\
\hline 3rd poverty quartile (medium high poverty) & 0.43 & 0.55 & 0.58 \\
\hline 4th poverty quartile (high poverty) & 0.39 & 0.52 & 0.50 \\
\hline (4) Two randomly chosen sisters - 1970-1974 & 0.59 & 0.61 & 0.61 \\
\hline 1st poverty quartile (low poverty) & 0.59 & 0.62 & 0.62 \\
\hline 2nd poverty quartile (medium low poverty) & 0.53 & 0.58 & 0.59 \\
\hline 3rd poverty quartile (medium high poverty) & 0.58 & 0.62 & 0.60 \\
\hline 4th poverty quartile (high poverty) & 0.64 & 0.63 & 0.64 \\
\hline (4) Correlation between mother and child & 0.04 & 0.20 & 0.16 \\
\hline 1st poverty quartile (low poverty) & 0.04 & 0.20 & 0.16 \\
\hline 2nd poverty quartile (medium low poverty) & 0.04 & 0.20 & 0.16 \\
\hline 3rd poverty quartile (medium high poverty) & 0.04 & 0.20 & 0.16 \\
\hline 4th poverty quartile (high poverty) & 0.06 & 0.20 & 0.16 \\
\hline
\end{tabular}

Notes: The poverty quartile refers to the percentage of households in poverty in the zip code of the child's birth (2) or the mother's birth (3 and 4). 
Table 3: Effect of Mother's Birth Weight on Child Birth Weight, Mother's born 1970-197،

\begin{tabular}{lcccccc} 
A: All Children & \multicolumn{1}{l}{} \\
\hline & {$[1]$} & {$[2]$} & {$[3]$} & {$[4]$} & {$[5]$} & {$[6]$} \\
\hline 1. Child's Low bw on Mother's & 0.038 & 0.032 & 0.029 & 0.028 & 0.028 & 0.028 \\
low bw & {$[.001]$} & {$[.001]$} & {$[.003]$} & {$[.003]$} & {$[.003]$} & {$[.003]$} \\
\hline 2. Child's bw on Mother's bw & 0.228 & 0.211 & 0.2 & 0.199 & 0.2 & 0.2 \\
& {$[.001]$} & {$[.001]$} & {$[.003]$} & {$[.003]$} & {$[.003]$} & {$[.003]$} \\
\hline 3. Child's log bw on Mother's & 0.205 & 0.185 & 0.172 & 0.171 & 0.172 & 0.171 \\
log bw & {$[.001]$} & {$[.001]$} & {$[.004]$} & {$[.004]$} & {$[.004]$} & {$[.004]$} \\
\hline Child Race, Sex, and Yr. Birth & & $\mathrm{Y}$ & $\mathrm{Y}$ & $\mathrm{Y}$ & $\mathrm{Y}$ & $\mathrm{Y}$ \\
Grandmother fixed effects & & & $\mathrm{Y}$ & $\mathrm{Y}$ & $\mathrm{Y}$ & $\mathrm{Y}$ \\
Poverty in mother's zip code & & & & $\mathrm{Y}$ & $\mathrm{Y}$ & $\mathrm{Y}$ \\
brth. & & & & & & $\mathrm{Y}$ \\
Mother age education and & & & & & & $\mathrm{Y}$ \\
parity & & & & & $\mathrm{Y}$ \\
Mother current zip & & & & & & \\
\hline
\end{tabular}

\section{B: Whites Only}

\begin{tabular}{lcccccc}
\hline 1. Child's Low bw on Mother's & 0.027 & 0.027 & 0.022 & 0.021 & 0.021 & 0.021 \\
low bw & {$[.001]$} & {$[.001]$} & {$[.003]$} & {$[.003]$} & {$[.003]$} & {$[.003]$} \\
\hline 2. Child's bw on Mother's bw & 0.208 & 0.208 & 0.198 & 0.196 & 0.199 & 0.198 \\
& {$[.001]$} & {$[.001]$} & {$[.003]$} & {$[.003]$} & {$[.003]$} & {$[.003]$} \\
\hline 3. Child's log bw on Mother's & 0.184 & 0.185 & 0.170 & 0.168 & 0.170 & 0.170 \\
log bw & {$[.001]$} & {$[.001]$} & {$[.004]$} & {$[.004]$} & {$[.004]$} & {$[.004]$} \\
\hline Child Race, Sex, and Yr. Birth & & $\mathrm{Y}$ & $\mathrm{Y}$ & $\mathrm{Y}$ & $\mathrm{Y}$ & $\mathrm{Y}$ \\
Grandmother fixed effects & & & $\mathrm{Y}$ & $\mathrm{Y}$ & $\mathrm{Y}$ & $\mathrm{Y}$ \\
Poverty in mother's zip code & & & & $\mathrm{Y}$ & $\mathrm{Y}$ & $\mathrm{Y}$ \\
brth. & & & & & $\mathrm{Y}$ & $\mathrm{Y}$ \\
Mother age education and & & & & & & $\mathrm{Y}$ \\
parity & & & & & &
\end{tabular}




\section{C: Blacks Only}

\begin{tabular}{lcccccc}
\hline 1. Child's Low bw on Mother's & 0.056 & 0.054 & 0.041 & 0.042 & 0.041 & 0.040 \\
low bw & {$[.005]$} & {$[.005]$} & {$[.010]$} & {$[.010]$} & {$[.010]$} & {$[.010]$} \\
\hline 2. Child's bw on Mother's bw & 0.207 & 0.207 & 0.193 & 0.193 & 0.192 & 0.19 \\
& {$[.004]$} & {$[.004]$} & {$[.013]$} & {$[.013]$} & {$[.013]$} & {$[.013]$} \\
\hline 3. Child's log bw on Mother's & 0.181 & 0.180 & 0.154 & 0.153 & 0.151 & 0.150 \\
log bw & {$[.005]$} & {$[.005]$} & {$[.017]$} & {$[.017]$} & {$[.017]$} & {$[.017]$} \\
\hline Child Race, Sex, and Yr. Birth & & $\mathrm{Y}$ & $\mathrm{Y}$ & $\mathrm{Y}$ & $\mathrm{Y}$ & $\mathrm{Y}$ \\
Grandmother fixed effects & & & $\mathrm{Y}$ & $\mathrm{Y}$ & $\mathrm{Y}$ & $\mathrm{Y}$ \\
$\begin{array}{l}\text { Poverty in mother's zip code } \\
\text { brth. }\end{array}$ & & & $\mathrm{Y}$ & $\mathrm{Y}$ & $\mathrm{Y}$ \\
Mother age education and & & & & & & $\mathrm{Y}$ \\
parity & & & & & $\mathrm{Y}$ \\
Mother current zip & & & & & $\mathrm{Y}$ \\
\hline
\end{tabular}

Note: Standard errors in parenthesis. 
Table 4: Interaction of Mother's Birth Weight and SES Measured at Mother's Birth

\begin{tabular}{lcccc}
\hline & LBW on LBW & LBW on LBW & BW on BW & BW on BW \\
\hline Model 1: Mother's Poverty & & & & \\
Group 1 (Low Poverty)*Mom BW & 0.0325 & 0.0302 & 0.211 & 0.198 \\
& {$[0.0020]$} & {$[.0037]$} & {$[.002]$} & {$[.004]$} \\
Group 2 (High Poverty)*Mom BW & 0.0386 & 0.0319 & 0.213 & 0.203 \\
& {$[0.0037]$} & {$[.0060]$} & {$[.004]$} & {$[.006]$} \\
Group 2 (High Poverty) Main Effect & 0.0043 & 0.0038 & -30.25 & -30.82 \\
& {$[.0008]$} & {$[.0016]$} & {$[14.8]$} & {$[15.54]$} \\
F-Test Group 1*Mom BW = & 0.16 & 0.82 & 0.57 & 0.48 \\
Group 2*Mom BW, (p-value) & & & & \\
Standard Controls & $\mathrm{Y}$ & $\mathrm{Y}$ & $\mathrm{Y}$ & $\mathrm{Y}$ \\
Grand Mother fixed effects & & & & $\mathrm{Y}$ \\
Model 2: Mother's Income & & & & \\
Group 1 (Low Income)*Mom BW & 0.029 & 0.022 & 0.213 & 0.192 \\
& {$[0.0044]$} & {$[.0007]$} & {$[.004]$} & {$[.008]$} \\
Group 2 (High Income)*Mom BW & 0.034 & 0.031 & 0.212 & 0.201 \\
& {$[0.0019]$} & {$[.0067]$} & {$[.002]$} & {$[.003]$} \\
Group 2 (High Poverty) Main Effect & -0.0027 & -0.0011 & -15 & -25.9 \\
F-Test Group 1*Mom BW = & {$[0.0010]$} & {$[.0018]$} & {$[.17 .0]$} & {$[20.8]$} \\
Group 2*Mom BW, (p-value) & 0.31 & 0.27 & 0.27 & 0.31 \\
Standard Controls & & & & $\mathrm{Y}$ \\
Grand Mother fixed effects & $\mathrm{Y}$ & $\mathrm{Y}$ & $\mathrm{Y}$ & $\mathrm{Y}$ \\
\hline
\end{tabular}

Note: Standard errors in parenthesis. Standard controls include baby's sex, race, and year. 
Table 5: Interaction of Mother's Birth Weight and SES Measured at Child's Birth (only interactions with mother's birth weight are shown).

\begin{tabular}{|c|c|c|c|c|}
\hline \multirow{2}{*}{ Model 1: Mother's Poverty } & \multicolumn{3}{|c|}{ LBW on LBW LBW on LBW BW on BW } & BW on BW \\
\hline & & & & \\
\hline \multirow[t]{2}{*}{ Group 1 (Low Poverty)*Mom BW } & 0.0287 & 0.0242 & 0.211 & 0.198 \\
\hline & {$[0.0018]$} & {$[.0031]$} & {$[.002]$} & {$[.003]$} \\
\hline \multirow[t]{2}{*}{ Group 2 (High Poverty)*Mom BW } & 0.042 & 0.0404 & 0.209 & 0.199 \\
\hline & {$[0.0033]$} & [.0048] & {$[.003]$} & {$[.0065]$} \\
\hline \multirow[t]{2}{*}{ Group 2 (High Poverty) Main Effect } & 0.0082 & 0.0051 & -34.19 & -26.64 \\
\hline & [.0008] & {$[.0012]$} & [12.88] & [18.34] \\
\hline \multicolumn{4}{|l|}{ Group 2*Mom BW, (p-value) } & 0.9 \\
\hline Standard Controls & Y & Y & Y & Y \\
\hline Grand Mother fixed effects & & Y & & Y \\
\hline \multicolumn{5}{|l|}{ Model 2: Mother's Income } \\
\hline \multirow[t]{2}{*}{ Group 1 (Low Income)*Mom BW } & 0.04 & 0.034 & 0.205 & 0.194 \\
\hline & {$[0.0033]$} & {$[.0004]$} & {$[.003]$} & {$[.005]$} \\
\hline \multirow[t]{2}{*}{ Group 2 (High Income)*Mom BW } & 0.029 & 0.026 & 0.212 & 0.201 \\
\hline & {$[0.0019]$} & {$[.0031]$} & {$[.002]$} & {$[.003]$} \\
\hline \multirow[t]{2}{*}{ Group 2 (High Poverty) Main Effect } & -0.0083 & -0.0057 & 14.8 & -1.7 \\
\hline & [0.0008] & {$[.0012]$} & {$[.17 .0]$} & {$[20.8]$} \\
\hline $\begin{array}{l}\text { F-Test Group } 1 * \text { Mom BW }= \\
\text { Group } 2 * \text { Mom BW, (p-value) }\end{array}$ & 0.001 & 0.16 & 0.06 & 0.2 \\
\hline Standard Controls & Y & Y & Y & Y \\
\hline Grand Mother fixed effects & & $\mathrm{Y}$ & & $\mathrm{Y}$ \\
\hline
\end{tabular}

Note: Standard errors in parenthesis. Standard controls include baby's sex, race, and year. 
Table 6: Effect of Low Birth Weight and SES at Mother's Birth on SES at Child's Birth

\begin{tabular}{|c|c|c|c|c|c|c|}
\hline \multirow{2}{*}{\multicolumn{7}{|c|}{$\begin{array}{cccc}\text { All } & \text { All } & \text { White } & \text { White } \\
\text { A. Outcome=Income in zip code of residence at child's birth }\end{array}$}} \\
\hline & & & & & & \\
\hline \multirow[t]{2}{*}{ 1. Birth SES } & 0.151 & 0.128 & 0.152 & 0.129 & 0.125 & 0.112 \\
\hline & {$[.001]$} & {$[.002]$} & {$[.001]$} & {$[.002]$} & {$[.003]$} & {$[.007]$} \\
\hline \multirow[t]{2}{*}{ Low BW } & -162 & -105 & -162 & -102 & -215 & -54 \\
\hline & [19.15] & [20.46] & [22] & [23.46] & [23.28] & [40.19] \\
\hline \multirow[t]{2}{*}{ 2. Birth SES } & 0.149 & 0.128 & 0.152 & 0.129 & 0.125 & 0.112 \\
\hline & {$[.001]$} & [.001] & {$[.001]$} & [.002] & {$[.003]$} & {$[.007]$} \\
\hline \multirow[t]{2}{*}{ Birth weight } & 0.112 & 0.075 & 0.12 & 0.069 & 0.132 & 0.06 \\
\hline & {$[.008]$} & {$[.009]$} & {$[.008]$} & {$[.010]$} & {$[.018]$} & {$[.022]$} \\
\hline \multicolumn{7}{|c|}{ B. Outcome=Zip code of residence at child's birth is high poverty } \\
\hline 1. Birth SES & -0.038 & -0.0337 & -0.038 & -0.033 & -0.048 & -0.0427 \\
\hline$[\$ 10,000]$ & [.0003] & [0.00049] & {$[.00034]$} & [.0005] & [.0013] & {$[.00237]$} \\
\hline \multirow[t]{2}{*}{ Low BW } & 0.0056 & 0.004 & 0.0052 & 0.0035 & 0.0082 & 0.0027 \\
\hline & {$[0.00045]$} & [0.00050] & [0.0005] & {$[0.00056]$} & [0.00128] & [0.0014] \\
\hline \multicolumn{7}{|c|}{ C. Outcome=Mother's education at child's birth } \\
\hline \multirow[t]{2}{*}{ 1. Birth SES } & 0.1548 & 0.0836 & 0.1749 & 0.0988 & 0.13 & 0.0789 \\
\hline & [0.0069] & {$[0.01]$} & {$[0.0073]$} & {$[0.0106]$} & [0.0204] & {$[0.0369]$} \\
\hline \multirow[t]{2}{*}{ Low BW } & -0.1256 & -0.0765 & -0.1307 & -0.0677 & -0.1345 & -0.096 \\
\hline & [0.0098] & {$[0.0102]$} & {$[0.0111]$} & {$[0.0115]$} & {$[0.0198]$} & {$[0.0218]$} \\
\hline Standard Controls & Y & Y & Y & Y & Y & Y \\
\hline \multicolumn{2}{|c|}{ Grand Mother Fixed Effects } & Y & & Y & & Y \\
\hline
\end{tabular}

Notes: Standard errors in parenthesis.

Median family income as of 1970 Census in zip code of mother's birth: $\$ 10,096(3,254)$.

Median family income as of 1990 Census in zip code of residence at child's birth: $\$ 53,769(20,664)$.

We convert 1990 dollars to real 1970 dollars before estimating the models in the first panel.

Controls include child's sex, race and year of child's birth. 
Table 7: The Effect of low birth weight interacted with SES at Mother Birth on SES at Child Birth. Outcome is income. Birth SES is grouped in 2 Groups

\begin{tabular}{|c|c|c|c|c|}
\hline & \multicolumn{4}{|c|}{ All } \\
\hline & LBW & BW & LBW & BW \\
\hline \multirow[t]{2}{*}{ Interaction with [Birth SES is low] } & -238 & 0.151 & -155 & 0.091 \\
\hline & [47] & [0.019] & [47] & {$[0.02]$} \\
\hline \multirow[t]{2}{*}{ Interaction with [Birth SES is high] } & -147 & 0.107 & -93 & 0.073 \\
\hline & [37] & {$[0.008]$} & [22] & {$[0.009]$} \\
\hline \multirow[t]{2}{*}{ Main Effect: [birth SES is High] } & 1168 & 1322 & 956 & 1020 \\
\hline & {$[13]$} & {$[72]$} & [17] & {$[78]$} \\
\hline \multirow{2}{*}{$\begin{array}{l}\text { F-Test: group } 1 \text { = group } 2 \\
\text { (p-value) }\end{array}$} & 0.07 & 0.03 & 0.23 & 0.42 \\
\hline & \multicolumn{4}{|c|}{ Whites } \\
\hline \multirow[t]{2}{*}{ Interaction with [Birth SES is low] } & -247 & 0.169 & -124 & 0.054 \\
\hline & [58] & {$[0.023]$} & [59] & {$[0.024]$} \\
\hline \multirow[t]{2}{*}{ Interaction with [Birth SES is high] } & -147 & 0.113 & -98 & 0.073 \\
\hline & [24] & [0.009] & {$[25]$} & {$[0.01]$} \\
\hline \multirow[t]{2}{*}{ Main Effect: [birth SES is High] } & 1162 & 1354 & 924 & 859 \\
\hline & [14] & {$[86]$} & {$[20]$} & [93] \\
\hline \multirow{2}{*}{$\begin{array}{l}\text { F-Test: group } 1 \text { = group } 2 \\
\text { (p-value) }\end{array}$} & 0.11 & 0.02 & 0.67 & 0.47 \\
\hline & \multicolumn{4}{|c|}{ Blacks } \\
\hline \multirow[t]{2}{*}{ Interaction with [Birth SES is low] } & -305 & 0.166 & -87 & 0.067 \\
\hline & {$[71]$} & {$[0.035]$} & {$[78]$} & {$[0.041]$} \\
\hline \multirow[t]{2}{*}{ Interaction with [Birth SES is high] } & -189 & 0.122 & -40 & 0.057 \\
\hline & [42] & {$[0.20]$} & [46] & {$[0.024]$} \\
\hline \multirow[t]{2}{*}{ Main Effect: [birth SES is High] } & 1098 & 1249 & 1019 & 1057 \\
\hline & {$[28]$} & {$[132]$} & {$[48]$} & [160] \\
\hline $\begin{array}{l}\text { F-Test: group } 1 \text { = group } 2 \\
\text { (p-value) }\end{array}$ & 0.16 & 0.28 & 0.6 & 0.83 \\
\hline Standard Controls & $\mathrm{Y}$ & $\mathrm{Y}$ & $\mathrm{Y}$ & $\mathrm{Y}$ \\
\hline GM Fixed Effects & & & $\mathrm{Y}$ & $\mathrm{Y}$ \\
\hline
\end{tabular}

Note: Standard errors in parenthesis. 
Appendix Table 1: Relationship between SES in Zip Code of Residence and SES in Zip Code of Hospital: data for 1989-2001

\begin{tabular}{|c|c|c|c|c|}
\hline & \multicolumn{2}{|c|}{ Correlations } & \multicolumn{2}{|c|}{$\begin{array}{c}\text { Regression } \\
\text { Dependent variable }\end{array}$} \\
\hline & $\begin{array}{c}\text { Poverty in } \\
\text { [1] }\end{array}$ & $\begin{array}{c}\text { Income } \\
\text { [2] }\end{array}$ & $\begin{array}{c}\text { Poverty } \\
\text { [3] }\end{array}$ & $\begin{array}{c}\text { Income } \\
\text { [4] }\end{array}$ \\
\hline \multicolumn{5}{|l|}{ All } \\
\hline Poverty in Zip Code of Residence & 0.475 & & $\begin{array}{c}0.46 \\
{[.019]}\end{array}$ & \\
\hline Income in Zip Code of Residence & & 0.549 & & $\begin{array}{c}.50 .0 \\
{[.019]}\end{array}$ \\
\hline \multicolumn{5}{|l|}{ Whites } \\
\hline Poverty in Zip Code of Residence & 0.471 & & $\begin{array}{r}0.485 \\
{[.023]}\end{array}$ & \\
\hline Residence Income & & 0.557 & & $\begin{array}{l}0.497 \\
{[.019]}\end{array}$ \\
\hline \multicolumn{5}{|l|}{ Blacks } \\
\hline Poverty in Zip Code of Residence & 0.386 & & $\begin{array}{l}0.385 \\
{[.026]}\end{array}$ & \\
\hline Residence Income & & 0.374 & & $\begin{array}{l}0.395 \\
{[.028]}\end{array}$ \\
\hline Controls & & & $\mathrm{Y}$ & $\mathrm{Y}$ \\
\hline
\end{tabular}

Poverty Quartile of Zipcode of Residence, 4=highest

\begin{tabular}{l|rrrr|r} 
& \multicolumn{1}{c}{1} & \multicolumn{1}{c}{2} & \multicolumn{1}{c}{ Total } \\
\hline Zipcode of hospital lowest poverty quartile & 182074 & 74935 & 61688 & 39683 & 358380 \\
Zipcode of hosp. 2nd lowest poverty quartile & 97270 & 136231 & 83743 & 47357 & 364601 \\
Zipcode of hosp. 3rd highest poverty quartile & 46296 & 91462 & 134805 & 77787 & 350350 \\
Zipcode of hosp. highest poverty quartile & 31796 & 55287 & 80976 & 191668 & 359727 \\
\hline Total & 357436 & 357915 & 361212 & 356495 & 433058
\end{tabular}

Notes: Standard errors in parenthesis. 
Appendix Table 2: Distribution of Distance Between Zip Code of Residence and Zip Code of Hospital based on 1989-2001 data

\begin{tabular}{lccc}
\hline & All & Whites & Blacks \\
& {$[1]$} & {$[2]$} & {$[3]$} \\
\hline 10 Percentile & 0 & 0 & 0 \\
25 Percentile & 2.7 & 2.7 & 1.4 \\
50 Percentile & 5.4 & 5.5 & 5 \\
75 Percentile & 10.3 & 10.6 & 8.4 \\
90 Percentile & 17.9 & 18.6 & 12.9 \\
\hline
\end{tabular}

Notes: Unit of measurement is miles. 
Figure 1: The Relationaship between Mother Birth Weight (x-axis) and Child Birth Weight (y-axis), by Income Level

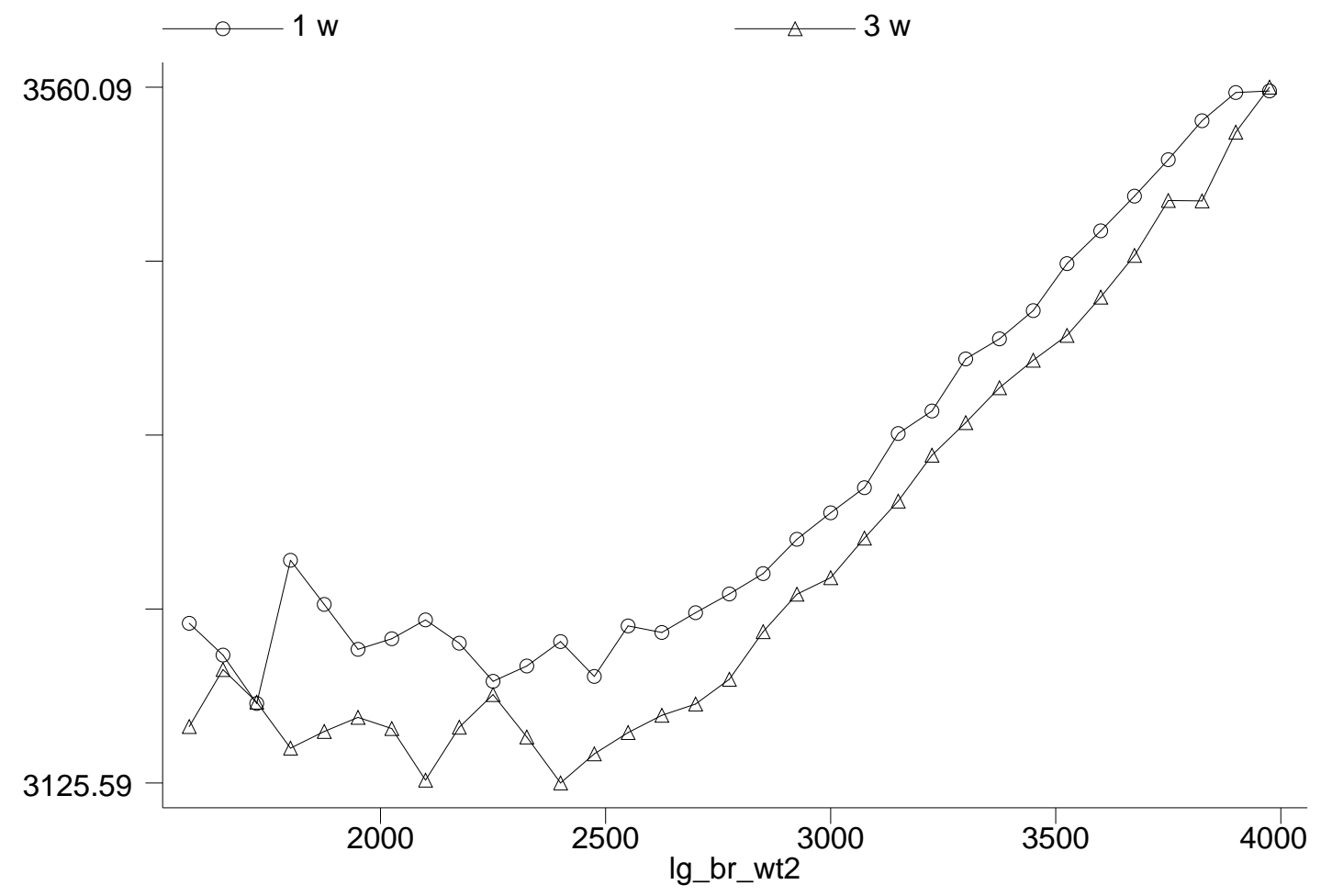

Note: The top line is for mothers born in high income areas; the bottom line is for mothers born in low income areas. 